\section{Analogía, teoría de los préstamos y responsabilidad del Estado*}

Analogy, borrowing theory and state liability

\section{Maximiliano Rafael Calderón}

\section{RESUMEN}

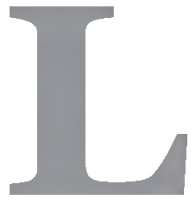

a ley nacional de responsabilidad del Estado no es aplicable en la provincia de Córdoba por vía analógica (dada su pertenencia a diferentes sistemas legislativos), pero podría acudirse a sus soluciones mediante la teoría de los préstamos.

Palabras clave: responsabilidad civil; Estado; analogía; teoría de los préstamos; federalismo.

\section{ABSTRACT}

The national law of state liability is not applicable in the province of Córdoba by analogy (given their membership in different legislative systems), but its solutions could be used through the borrowing theory. .

Keywords: civil liability; State; analogy; borrowing theory; federalism.

${ }^{*}$ El presente aporte corresponde a una investigación realizada en el marco de la Secretaría de Posgrado e Investigación (Universidad Católica de Córdoba).
Maximiliano Rafael Calderón calderon@marquezycalderon.com

Universidad Católica de Córdoba ARGENTINA
COMO CITAR ESTE ARTÍCULO Calderón M, R. (2021). Analogía, teoría de los préstamos y responsabilidad del Estado. Revista de la Facultad de Ciencias Económicas, 26(1), 47 - 58. http://dx.doi.org/10.30972/rfce.2615029

\section{(1) $(\Theta \Theta$}

https://ereativecommons org /licenses/by-ne-nd/40/ Revista de la Facultad de Ciencias Económica ISSN $1668-6357$ (formato impreso) ISSN 1668-6365 (formato digital) por Facultad de Ciencias Económicas Universidad Nacional del Nordeste (UNNE) Argentina se distribuye bajo una Licencia Creative Commons Atribución - No Comercial - Sin Obra Derivada 4.o Internacional. 


\section{EL TEMA}

\section{(a). La regla de exclusión normativa}

El Código Civil y Comercial dispone en su art. 1764 (Inaplicabilidad de normas) que "Las disposiciones del Capítulo 1 de este Título no son aplicables a la responsabilidad del Estado de manera directa ni subsidiaria". La remisión se refiere al Capítulo 1 ("Responsabilidad Civil") del Título V ("Otras fuentes de las obligaciones") del Libro Tercero ("Derechos Personales").

Esta norma: (i) excluye la aplicación directa del Código a la responsabilidad del Estado, atribuyéndola a las disposiciones de derecho administrativo nacional o local (art. 1765, Cód. Civ. y Com.)'; (ii) excluye la aplicación subsidiaria del Código a la responsabilidad del Estado, es decir, aquella que procedería en ausencia de una regulación especial por parte de estas disposiciones de derecho administrativo ${ }^{2}$; (iii) no se pronuncia acerca de la aplicación analógica del Código a la responsabilidad del Estado.

\section{(b). La laguna regulatoria en la provincia de Córdoba y el recurso a la analogía}

A los fines de desarrollar nuestra línea de análisis, tomaremos como ejemplo la situación de la provincia de Córdoba.

La provincia de Córdoba no ha dictado una ley regulatoria de la responsabilidad del Estado.

Esto determina una laguna normativa sobre el punto, pues: (i) el Código Civil y Comercial no es aplicable; (ii) no existen normas de derecho administrativo local que regulen el punto.

En este contexto, hasta tanto el Poder Legislativo local supla esta omisión legislativa, los jueces deben resolver las causas acudiendo a diversos métodos de integración normativa, entre ellos la analogía (art. 2, Cód. Civ. y Com.).

Pero: ¿cuál es la norma cuya aplicación analógica corresponde realizar para llenar dicha laguna? ¿El Código Civil y Comercial? ¿La ley nacional de responsabilidad del Estado 26.944? ¿Otras leyes de responsabilidad del Estado dictadas por otras jurisdicciones locales (provincias, Ciudad Autónoma de Buenos Aires, municipios)?

\section{LA APLICACIÓN ANALÓGICA DEL CÓDIGO CIVIL Y COMERCIAL}

\section{(a). La discusión doctrinaria.}

¿Es posible aplicar analógicamente el Código Civil y Comercial en casos de responsabilidad del Estado atinentes a la competencia provincial?

\footnotetext{
${ }^{1}$ En la aplicación directa, las normas juegan "en razón de pertinencia y no ante la ausencia de normas de derecho público relativas al problema" (Cuadros, 2013, p. 1).

2 La característica central de esta aplicación supletoria reside en que "el derecho supletorio pasa a cubrir la carencia normativa de un modo directo, sin sufrir modificaciones, de tal modo que el juez no elabora la norma, sino que la aplica tal como es" (De la Fuente, 1994, p. 983).
} 
Sobre el punto, la doctrina no es pacífica: (i) para algunos autores, la aplicación es dudosa, pues señalan moderadamente que "es válido discutir la aplicación del recurso de la analogía" (Tanzi, Ubiria y Fossaceca, 2013, p. 1); (ii) para otros, es procedente la aplicación analógica (Balbín, 2016, pp. 102-103; Cassagne, 2014, p. 885; Biglieri, 2014, p. 728; Sarmiento García, 2014, p. 563; Perrino, 2015, pp. 53-56; Correa, 2014, pp. 88-89; Pizarro, 2013, p. 855; Tonelli y Oyhanarte, 2013, p. 809); (iii) para una última posición, esta aplicación analógica no procedería, pues la legislación habría partido de "la premisa de distinguir de raíz la responsabilidad del Estado y la gobernada por el Código Civil" por lo que no podrían ser ulteriormente asimiladas sobre la idea de que son supuestos similares (Brodsky, Donato Bruno y Petrinelli, 2014, p. 93).

\section{(b). Nuestra opinión}

Por nuestra parte, entendemos:

- Que el Código Civil y Comercial sí es aplicable analógicamente en materia de responsabilidad del Estado.

Esto es así, al menos por las siguientes razones: (i) una interpretación a contrario del art. 1764 Cód. Civ. y Com. indica que, habiéndose vedado expresamente otros modos de aplicación normativa (directa y subsidiaria) y callando sobre la analogía, surge tácitamente la intención legislativa de admitir esta vía; (ii) el art. 2 Cód. Civ. y Com. acepta ampliamente el recurso a la analogía, por lo que a falta de normas específicamente prohibitivas, debe estarse por su vigencia; (iii) una interpretación conforme del sistema ${ }^{3}$, tendiente a permitir su mejor funcionamiento y salvaguardar la efectiva vigencia de los derechos y garantías constitucionales, impone escoger la opción hermenéutica que ayuda a conformar un sistema resarcitorio razonable, y no aquella que lo enerva y obstruye su funcionamiento; en este marco la interpretación más razonable es la que admite el mecanismo analógico ${ }^{4}$; (iv) por más que el legislador haya querido diferenciar la responsabilidad del Estado de otros supuestos de responsabilidad civil, esto no significa que haya provocado un quiebre epistémico que impida recurrir al bagaje conceptual del derecho común; en tal sentido, el afán diferenciador del legislador se satisface con las posibilidades de ajuste que específicamente admite el procedimiento analógico, a diferencia de otros modelos que suponen aplicación indiferenciada, tal como veremos a continuación.

- Que esta aplicación analógica podrá tener lugar en diversos casos: (i) si existe una laguna normativa, por no haberse previsto el tema en la legislación directamente aplicable ${ }^{5}$; (ii) si

\footnotetext{
${ }^{3}$ Aquella que hace compatible a una norma con los parámetros constitucionales. Esta forma de interpretar fue expresamente asumida por la Corte Suprema (vgr, in re "Casal", Fallos 328:3399).

${ }^{4}$ Dicho de un modo más simple: reputamos más constructivo, ante una solución normativa dada, realizar los esfuerzos necesarios para generar una aplicación razonable y no lesiva de los derechos y garantías constitucionales, y no desgañitarnos criticando lo que no nos gusta y, lo que es peor, ensayando exégesis normativas que conducen a una mayor lesión de derechos.

${ }^{5}$ A nivel local, la ausencia de regulación es total. A nivel nacional, las lagunas normativas se circunscriben a aquellas materias no regladas por la ley 26.944 .
} 
existen lagunas axiológicas, por haber dictado el legislador normas superinclusivas que no contemplan propiedades relevantes que justificaban la aplicación de un tratamiento diferenciado. ${ }^{6}$

- Que esta aplicación deberá hacerse siguiendo las directrices que desde vieja data ha fijado la C.S.J.N. in re "Los Lagos" y que se sintetizan en estas dos afirmaciones de la Corte: (i) "nada obsta" a la aplicación analógica de los institutos de derecho civil en materia administrativa; (ii) esta aplicación debe hacerse "con las discriminaciones impuestas por la naturaleza propia de lo que constituye la sustancia de esta última disciplina".

En palabras de De la Fuente: al aplicar la analogía "el juzgador, a partir de la disposición civil, elaborará una norma nueva y distinta, que antes no existía en el orden jurídico" (De la Fuente, 1984), lo que diferencia este supuesto de la aplicación subsidiaria o supletoria.

- Que este modo de proceder no es ajeno a las diversas ramas del derecho que se apoyan en los conceptos preexistentes del derecho civil, como da cuenta por caso la doctrina administrativista (Marienhoff, 1973, p. 719; Cassagne, 1984, pp. 743-744; Hutchinson, 2003, p. 421).

Esta interacción entre el derecho civil y el derecho público implica que la materia administrativa carezca de pureza y conlleve infiltraciones iusprivatistas, lo que llevó a acuñar la idea de los casos regidos "preponderantemente" por el derecho administrativo. ${ }^{8}$

\section{LA IMPOSIBILIDAD DE APLICACIÓN ANALÓGICA DE LA LNRE Y OTRAS NORMA PROVINCIALES}

Una discusión equivalente podría darse en torno a la aplicación analógica de la ley nacional de responsabilidad del Estado (LNRE) u otras leyes provinciales dictadas en la materia.

Existen autores que se han pronunciado a favor de esa posibilidad (Perrino, 2015, p. 257) y otros que se expidieron en contra (Balbín, 2016, pp. 119-120). Nos inclinamos por esta última postura.

Es que, como bien lo explica Balbín, la relación jurídica entre el bloque del derecho administrativo federal y el provincial es inexistente, habida cuenta de que cada uno de ellos actuará exclusivamente en su propio ámbito competencial, desplazando correlativamente al otro. De ahí que, a su criterio, "si el bloque del derecho administrativo de cualquier Estado provincial no resuelve ciertos casos (lagunas del derecho), no es plausible -en el marco de nuestro ordenamiento constitucional- recurrir al bloque de derecho administrativo federal o al de las otras provincias, con el fin de rellenar otras lagunas" (Balbín, 2016, p. 120).

\footnotetext{
${ }_{6}^{6}$ Por ejemplo, dentro de la ley 26.944, puede entenderse como superinclusiva la norma sobre responsabilidad del Estado por actos ilícitos, dado que pretende englobar todas las situaciones posibles sin diferenciar casos que merecen un tratamiento particular, tales como la responsabilidad por riesgo o vicio de la cosa.

${ }^{7}$ Fallos 190:142.

${ }^{8}$ T.S.J. Sala Contencioso Administrativa, "Manzanares", "Pochetino de Collado", "Moreno", "Morra", "Vicario", entre varios. Ver diversos trabajos citados en Sesin, 2011.
} 
La analogía supone la pertenencia de la norma positiva que regula una situación de hecho y la laguna normativa que se debe llenar al mismo sistema u ordenamiento jurídico. Cuando la norma es ajena al sistema normativo cuya omisión regulatoria debe resolverse, no puede ejercerse esta técnica de integración.

\section{LA TEORÍA DE LOS PRÉSTAMOS Y SU APLICACIÓN EN MATERIA DE RESPONSABILIDAD DEL ESTADO}

\section{(a). Aproximación al punto}

Sin embargo, la exclusión de la analogía no implica lisa y llanamente la imposibilidad de tomar referencialmente las reglas de la LNRE a los fines de resolver casos de responsabilidad del Estado suscitados en la provincia de Córdoba. Ello será factible a la luz de la teoría de los préstamos.

\section{(b). Caracterización}

Entendemos por "préstamo" al uso de derecho ajeno al sistema normativo directamente aplicable a fin de fundar una decisión. Esta definición alcanza: (i) el empleo por jueces nacionales de derecho extranjero; (ii) el empleo de jueces de una provincia de derecho de otra provincia o normas aplicables exclusivamente a la jurisdicción federal (Rosenkrantz, 2005, p. 72). Por razones de practicidad utilizaremos la expresión "derecho extranjero" para referirnos a ambos supuestos.

Podrían distinguirse, en cambio, de los "trasplantes", que suponen la adopción de una institución extranjera por parte de un cuerpo legislativo y de otros usos "no autoritativos" del derecho extranjero en los que el Tribunal menciona normas extranjeras (como evidencia de hechos, como fuente de conocimiento, a los fines de rechazar conscientemente un préstamo, etc.) (Rosenkrantz, 2005, pp. 87-88). En todos estos casos existe circulación de derecho extranjero.9

Algunas de las razones que se invocan para justificar esta práctica son las siguientes (Rosenkrantz, 2005, pp. 79-82): (i) la existencia de relaciones genéticas con el derecho extranjero, al mantener ambos una historia común (por ejemplo, la Constitución Nacional respecto de la Constitución de Estados Unidos, o el Código Civil respecto de su equivalente francés); (ii) la conveniencia de recurrir a criterios adoptados en el extranjero previa deliberación, lo que torna probable que se hayan identificado las soluciones correctas (Benjumea Gutiérrez, 2011, p. 117); (iii) la posibilidad de que el derecho extranjero genere un impulso suficiente para inducir a la deliberación colectiva, permitiendo a la comunidad un proceso de apropiación de normas que permita legitimarlas (Bömer, 2010, p. 1105).

${ }^{9}$ Se relaciona el tema con la teoría internacionalista de la judicial cross fertilization. 
En el derecho argentino, el recurso a estos préstamos es de vieja data, y se explica en parte en el hecho de que la Constitución Nacional reproduce disposiciones de la Constitución norteamericana.

La Corte Suprema recurrió a citas de derecho extranjero desde el pretérito $1877^{10}$; lo hizo en algunas de sus decisiones fundamentales ${ }^{11}$ y lo sigue haciendo contemporáneamente. $^{12}$

En materia de derecho del consumidor, la técnica fue abiertamente utilizada en el leading case "Halabi" diccional que esté a la altura de la evolución de las instituciones y a las exigencias actuales de la sociedad, no puede pasar desapercibida a los magistrados la experiencia recogida en otros sistemas jurídicos", exponiendo el sistema de acciones colectivas de Estados Unidos, España y Brasil y considerando aceptable en nuestro sistema jurídico "una acción colectiva con análogas características y efectos a la existente en el derecho norteamericano".

La Corte no trae a colación estos sistemas en un alarde de erudición: lo hace ante la necesidad de dar una respuesta jurisdiccional, $\mathrm{y}$ termina admitiendo en nuestro sistema una acción análoga a la receptada por el derecho norteamericano. Consideramos nítido el proceso de heterointegración normativa que exhibe éste razonamiento. ${ }^{14}$

En la provincia de Córdoba encontramos una admisión positiva de este modo de proceder, pues el art. 887 del Código de Procedimientos Civiles y Comerciales permite el recurso a "leyes análogas", lo que la doctrina procesal ha interpretado como permisivo de recurrir a leyes adjetivas de otras provincias o al Código Procesal Civil y Comercial de la Nación (Venica, 2005, p. 507).

\section{(c). Problematicidad}

Esta práctica, si bien es usual, no se encuentra en absoluto exenta de problemas.

Dejamos de lado, a los fines de este análisis, una primera cuestión, referida a la discusión en sí de qué debe entenderse como derecho extranjero ${ }^{15}$, y nos concentramos en el análisis puntual de las discusiones sobre la procedencia del método de los préstamos, considerado en sí mismo.

\footnotetext{
10 "De la Torre", Fallos 19:231.

11 "Sojo", Fallos 32:120; "Ercolano c/ Lanteri de Renshaw”, Fallos 136:161; “Avico c. De la Pesa”, Fallos 172:21.

12 "Montenegro", Fallos 303:1938; "Fiscal c/ Fernández", Fallos 313:1305; "Costa", Fallos 310:508; “Gesualdi”, Fallo $319: 3085$.

${ }^{13}$ C.S.J.N., Fallos 332:111.

14 Posteriormente, en el caso "Padec c. Swiss Medical" (LL 2013-E-290), la Corte insiste en esta asimilación a las acciones de clase del derecho estadounidenses, incurriendo en una asimilación que reputamos exagerada en tanto exige la supervisión de la subsistencia de idoneidad del representante (Considerando 16).

${ }^{15}$ En nuestro país, existe una polémica sobre este punto, específicamente referida al estatus de los tratados internacionales de derechos humanos (dotados de rango constitucional por el art. 75 inc. 23, Const. Nac., a partir de la reforma constitucional de 1994), y la posibilidad de considerarlos derecho nacional o extranjero. Esta discusión es sucedánea de otras controversias preexistentes en el seno del derecho internacional público, como el monismo y el dualismo. En nuestro país, la disputa encontró quienes consideraron que se trata de normas de derecho extranjero (Rosenkrantz, 2005) y quienes postulan lo contrario (Filippini, 2007).
} 
Explica Benjumea Gutiérrez (2011, pp. 113-119) que la referencia por la Corte de un país a las decisiones de una Corte extranjera es común, dándose en la jurisprudencia de Colombia, Irlanda, Sudáfrica, Canadá, Australia, Israel y el Reino Unido, lugares en que esta práctica no dio lugar a debates; por el contrario, en Estados Unidos, este recurso generó un intenso debate.

El mismo autor, refiriéndose a la interpretación constitucional de Estados Unidos, presenta tres actitudes posibles ante el derecho extranjero: (i) el modelo de resistencia, que rechaza el recurso al derecho comparado; (ii) el modelo de convergencia, que incorpora normas de derecho extranjero al derecho local; (iii) el modelo del engranaje, que admite la posibilidad de examinar el derecho extranjero a fin de indagar razones que pueden ser de utilidad en la resolución del problema a resolver.

Algunas objeciones que se plantean son las siguientes:

- Los préstamos suponen la imperatividad de normas adoptadas por otros países, lo que da lugar a un proceso heterónomo y violatorio de la regla de autogobierno, de acuerdo a la cual solamente estamos obligados a cumplir las reglas que son el resultado de decisiones colectivas de la entidad política a la que pertenecemos. ${ }^{16}$

Este planteo puede refutarse afirmando que el recurso al derecho extranjero no se produce mediante un mecanismo de sometimiento en el que el país receptor sufre pasivamente una invasión normativa. Por el contrario, quienes deciden traer a colación normas externas de manera voluntaria (sin estar sometidos a coacción volitiva) son los Tribunales, que forman parte del sistema institucional local.

- Los préstamos carecen de una justificación normativa que permita a los tribunales recurrir al derecho extranjero para fundar sus decisiones.

Una respuesta posible sería que los tribunales tampoco tienen prohibido recurrir al derecho extranjero, del mismo modo en que pueden recurrir a múltiples elementos de análisis (doctrina, jurisprudencia, principios, etc.) más allá de las normas.

Esta objeción quedaría completamente diluida en el marco de un criterio de pertenencia de normas a un sistema jurídico apoyado, antes que en la territorialidad o la identidad del legislador, en la decisión de los órganos que tienen a su cargo la aplicación del derecho, de modo que si éstos órganos toman una norma extranjera como fundamento decisivo, esta norma pertenecería al sistema. ${ }^{17}$

- La idea de recurrir a préstamos sería una excentricidad, ajena de arraigo en nuestro sistema.

Sin embargo, la práctica jurisprudencial y el pensamiento jurídico dominante en nuestro sistema jurídico acreditan que la referencia al derecho extranjero goza de carta de ciudadanía en nuestro sistema Los préstamos carecen de una justificación normativa que permita a los tribunales recurrir al derecho extranjero para fundar sus decisiones.

\footnotetext{
${ }^{16}$ Consideramos esta apreciación errónea, por cuanto los tratados internacionales de derechos humanos no pueden reputarse derecho extranjero (Filippini, 2007, pp. 191-202)

${ }^{17}$ Criterios de Raz y Ross (Nino, 1984, p. 127).
} 
Una respuesta posible sería que los tribunales tampoco tienen prohibido recurrir al derecho extranjero. ${ }^{18}$

- El recurso a préstamos desconoce el hecho de la diversidad, que marca la existencia de particularidades de cada país, por lo que el derecho positivo de cada Estado debe ser, por definición, particular y territorial.

Al respecto cabría señalar: (i) que esta crítica sería atendible, solo en caso de que el préstamo se hiciera como una traslación mecánica, acrítica (y, por ello, irracional) del derecho extranjero; pierde vigor, en cambio, ante un empleo mesurado y razonable, que realice un juicio de pertinencia y compatibilidad de las soluciones foráneas con los problemas locales; (ii) que, además de problemas específicos de cada país, existen temáticas universales (por ejemplo, la protección de los derechos humanos fundamentales) en los que la diversidad de los países y sus regímenes jurídicos carece de trascendencia Los préstamos carecen de una justificación normativa que permita a los tribunales recurrir al derecho extranjero para fundar sus decisiones.

Una respuesta posible sería que los tribunales tampoco tienen prohibido recurrir al derecho extranjero (Benjumea Gutiérrez, 2011, pp. 132-137).

\section{(c). El estatus de los préstamos en la decisión}

No hemos profundizado hasta el momento la indicación de cuál es el estatus que se le atribuye a los préstamos en la jurisprudencia: ¿Fundamento dirimente? ¿Argumento complementario? ¿Ilustración irrelevante o mera muestra de erudición?

Benjumea Gutiérrez (2011, pp. 132-137) señala que, en la jurisprudencia de la Corte norteamericana, las fuentes extranjeras no fueron la razón de la decisión, pero tampoco comentarios innecesarios hechos "de paso", precisando más adelante (2011, p. 156) que operaron como información, sin valor de precedente, denotando una "permeabilidad al conocimiento agregado del hombre".

Particularmente, no dudamos en que dichos préstamos constituyen "fuentes de derecho", sobre la base de dos fundamentos:

- Teóricamente, entendemos la búsqueda de fuentes como una búsqueda de criterios de objetividad o tópicos jurídicos, comprendiendo el modo de surgimiento y desarrollo del derecho tanto como su fundamento, calificando como fuentes en tanto entrañen una razón por la cual se ha decidido de un determinado modo y no de otro diferente. ${ }^{19}$

Si el recurso al derecho extranjero es (individualmente o sumada a otros argumentos) la razón suficiente de una decisión, engasta como fuente en esta comprensión amplia que señalamos.

\footnotetext{
${ }^{18}$ Esto puede verificarse por diferentes carriles (lectura de jurisprudencia o de doctrina, por ejemplo). El recurso a los antecedentes norteamericanos (para la interpretación de la Constitución Nacional) y europeos (principalmente, el Código Civil francés y la doctrina desarrollada en su torno) constituye una prueba acabada.

${ }^{19}$ Tomamos estas ideas de Andruet, quien recurre a la noción de "Physis" (Andruet (h), 1993, p. 167).
} 
- Empíricamente, es posible verificar que los tribunales utilizan el derecho extranjero (legislación, jurisprudencia) como material normativo a ser considerado y con pretensiones competitivas de decidir la contienda, y no como un corpus innecesario de expresiones tangenciales.

Con todo, al tiempo de la decisión estas normas obtenidas por la vía de la teoría de los préstamos asumirán un valor complementario y subalterno frente a las reglas aplicables de manera directa, subsidiaria y analógica. ${ }^{20}$

\section{(d). Teoría de los préstamos y aplicación de normas sobre responsabilidad del Estado}

La teoría de los préstamos permite acudir a leyes de otras provincias sobre responsabilidad del Estado y a la LNRE, dado que habilita el recurso a normas no existentes en nuestro ordenamiento normativo, a fin de resolver casos regidos por nuestro sistema jurídico. En este sentido, implica un caso de importación de material jurídico no existente en un sistema normativo.

Si esta importación es considerada legítima (aún de manera polémica o bajo ciertas condiciones) respecto de ordenamientos jurídicos extranjeros, debe a fortiori reputarse válida cuando se realiza entre normas dictadas por otras entidades incorporadas al Estado federal argentino.

A más de la justificación epistémica y jurídica de esta teoría, se advierte su utilidad práctica: proporciona al Juez reglas de derecho que pueden ayudarlo a resolver casos de responsabilidad del Estado y carece de normas aplicables directa o subsidiariamente.

\section{CONCLUSIÓN FINAL}

El régimen de responsabilidad del Estado diseñado por el Código Civil y Comercial produjo, además de la fragmentación y la dispersión normativa, un vacío regulatorio en las provincias que no dictaron sus normas locales.

Entre otras técnicas de integración normativa, se encuentra la posibilidad de acudir a la analogía (art. 2, Cód. Civ. y Com.). Este método permite el empleo (analógico) de las normas del Código Civil y Comercial sobre responsabilidad civil a fin de regular la responsabilidad del Estado en la provincia de Córdoba.

No es posible en cambio aplicar analógicamente normas dictadas en otras provincias o a nivel nacional en materia de responsabilidad del Estado, pero ello no excluye su empleo mediante la teoría de los préstamos, con un valor normativo menguado pero alcanzando un estatus de fuente del derecho.

${ }^{20}$ La justificación de esta afirmación excede el marco objetivo propuesto para este trabajo. 


\section{REFERENCIAS BIBLIOGRÁFICAS}

Andruet (h), A. S. (1993). Estudios de Filosofia del Derecho. Alveroni: Córdoba.

Balbín, C. (2016). Impacto del Código Civil y Comercial en el derecho administrativo. Astrea: Buenos Aires.

Benjumea Gutiérrez, P. (2011). Críticas vacías: la controversia sobre el uso de fuentes extranjeras en la jurisprudencia de la Corte Suprema de los Estados Unidos. Revista Jurídica de la Universidad de Palermo, año 12, $\mathrm{n}^{\mathrm{o}}$ 1, 2011.

Biglieri, A. (2014). Tensión entre la Reforma del Código y la ley de responsabilidad del Estado proyectada. LL 2014-C-728.

Bömer, M. (2010). Préstamos y adquisiciones. La utilización del derecho extranjero como una estrategia de creación de autoridad democrática y constitucional, en Teoría y Crítica del Derecho Constitucional. Tomo II (Derechos). Abeledo Perrot: Buenos Aires.

Brodsky, J. M., Donato, B., Enzo E. y Petrinelli, L. A. (2014). La responsabilidad extracontractual del Estado en el Proyecto de Código Civil y Comercial de la Nación: un atajo hacia la irresponsabilidad estatal. DJ 25/06/2014, 93.

Cassagne, J. C. (1984). El acto administrativo. LL 1984-B, 743/744.

Cassagne, J. C. (2014). El fundamento constitucional de la responsabilidad del estado y su regulación por el Código Civil o por leyes administrativas. LL 2014-C-885.

Correa, J. L. (2014). Modificación por ley de la responsabilidad del Estado. Revista de Derecho de Daños, 2014-3. Rubinzal Culzoni: Santa Fe.

Cuadros, O. A. (2013). ¿Pueden las Provincias legislar en materia de responsabilidad patrimonial del Estado? - A propósito de la aparente falta de regulación de tal materia en el proyecto de código unificado Civil y Comercial. DJ 13/02/2013, 1.

De la Fuente, H. H. (1994). Posibilidad de modificar el Derecho civil para adaptarlo a los derechos especiales. LL 1994-B, 983. 
Filippini, L. (2007). El derecho internacional de los derechos humanos no es un préstamo Reflexiones sobre la crítica a los préstamos de Carlos F. Rosenkrantz. Revista Jurídica de la Universidad de Palermo, Año 8, $\mathrm{N}^{\circ}$ 1. Buenos Aires, Argentina.

Hutchinson, T. (2003). La teoría de las sanciones al acto administrativo defectuoso. (A propósito de los fallos "Ganadera los Lagos S.A." y "Pustelnik")". Colección de Análisis Jurisprudencial Elementos de Derecho Administrativo - Director: Tomás Hutchinson - Editorial LA LEY 2003, 421, Cita Online AR/DOC/282/2007.

Marienhoff, M. S. (1973). Tratado de Derecho Administrativo. Tomo IV. Abeledo-Perrot: Buenos Aires.

Nino, Carlos S. (1984). Introducción al análisis del derecho. Astrea: Buenos Aires.

Perrino, P. E. (2015). La responsabilidad del Estado y los Funcionarios Públicos. La Ley: Buenos Aires.

Pizarro, R. D. (2013). La responsabilidad del Estado y de los empleados y funcionarios públicos en el Anteproyecto y en el Proyecto de Código Civil de 2012. LL 2013-E, 855.

Rosenkrantz, C. F. (2005). En contra de los "Préstamos" y de otros usos "no autoritativos" del derecho extranjero. Revista Jurídica de la Universidad de Palermo, Año 6 (2005) No 1, p. 72.

Sarmiento García, J. H. (2014). Responsabilidad del Estado. Principios y proyecto de ley. LL 2014-B, 563 .

Sesín, D. J. (2011). La Admisibilidad del Contencioso Administrativo. Requisitos esenciales. Causales de inadmisión. Abeledo Perrot: Córdoba.

Tanzi, S. Y, Ubiría, F. A. y Fossaceca, C.A. (h.). (2013). Responsabilidad del Estado: Reflexiones sobre la conveniencia de su regulación en el Código Civil. Elementos para un adecuado encuadramiento. DJ 18/12/2013, 1.

Tonelli, P. G. y Oyhanarte, M. (h.). (2013). Cuestión de la responsabilidad del Estado y sus funcionarios en el Proyecto de Código. LL 2013-B, 809.

Venica, O. H. (2005). Código Procesal Civil y Comercial de la provincia de Córdoba. Tomo VI, Córdoba. 


\section{CURRICULUM VITAE}

\section{Maximiliano Rafael Calderón}

Doctor en Derecho. Investigador Universidad Católica de Córdoba. Profesor Titular de Derecho Público Provincial y Municipal, Derecho Privado IV (Contratos), Derecho del consumidor y Derecho Privado VIII (Daños) en la Universidad Católica de Córdoba, Argentina.

calderon@marquezycalderon.com 